\title{
Violência contra crianças e adolescentes com deficiência: narrativas com conselheiros tutelares
}

\author{
Violence against children and adolescents with disabilities: \\ narratives with guardianship councilors
}

\author{
Martha Cristina Nunes Moreira ${ }^{1}$ \\ Olga Maria Bastos ${ }^{1}$ \\ Liliana Cabral Bastos ${ }^{2}$ \\ Ana Helena Rotta Soares ${ }^{1}$ \\ Waldir da Silva Souza ${ }^{3}$ \\ Rachel Niskier Sanchez ${ }^{1}$
}

\footnotetext{
${ }^{1}$ Departamento de Pediatria, Instituto Fernandes Figueira, Fundação Oswaldo Cruz. Av. Rui Barbosa 716/ IFF/Fiocruz Flamengo. 22.250-020 Rio de Janeiro RJ Brasil.

moreira@iff.fiocruz.br

${ }^{2}$ Departamento de Letras, Centro de Teologia e

Ciências Humanas,

Pontifícia Universidade

Católica do Rio de Janeiro.

${ }^{3}$ Faculdade de Sociologia,

Universidade Estácio de Sá.
}

\begin{abstract}
The article is based on Thompson's indepth hermeneutics with emphasis on meanings produced from narrative analysis of 15 guardianship councilors, seeking to interpret the significance of the councilor's function and ensuring the rights of children and adolescents with disabilities. The conclusion drawn is that certain generic discourses on this theme are presented as an inflexible core which reinforces the invisibility of the population and renders it more vulnerable. At the other extreme, the generic category of being "special" highlights the difficulties of the guardianship councilor in seeking strategies in the institutional network (health, leisure, education) for ensuring the rights and needs of this segment and their families, when failing to differentiate between the various categories of disability. Finally, the acquisition of knowledge by counselors related to this clientele depends greatly on the proximity of these counselors to health institutions that contribute in formulating strategies for guaranteeing rights that form networks. The situations of vulnerability to which counselors are exposed in the relationship between their mandate to respond to the violations suffered by the juvenile segment, and impotence to resolve them are stressed.

Key words Guardianship councilors, Narrative analysis, Violence against children and adolescents, Disability
\end{abstract}

Resumo Artigo focado na hermenêutica de profundidade de Thompson com recorte nos sentidos produzidos a partir da análise narrativa com 15 conselheiros tutelares visando interpretar os sentidos da função de conselheiro na garantia dos direitos de crianças e adolescentes com deficiência. Conclui-se que determinados discursos genéricos sobre este tema funcionam como um núcleo duro que reforça a invisibilidade desse público e o torna mais vulnerável. No outro extremo a categoria genérica "especial" fala das dificuldades do conselheiro tutelar em buscar na rede institucional (saúde, lazer, educação) estratégias dessas garantias e das necessidades deste segmento e de suas famílias, ao deixar de diferenciar as diversas categorias de deficiências. Por fim, as aquisições de conhecimento, por alguns conselheiros, relacionadas a essa clientela se dá muito em função da proximidade com instituições de saúde que contribuem na construção de estratégias de garantia de direitos que formam redes. Destacamos as situações de vulnerabilidade a que estão expostos os conselheiros na relação entre o mandato de responder às violações sofridas pelo segmento infanto-juvenil, $e$ a impotência resolutiva.

Palavras-chave Conselheiros tutelares, Análise narrativa, Violência contra crianças e adolescentes, Deficiência 


\section{Introdução}

Os Conselhos Tutelares, criados pelo Artigo 131 do Estatuto da Criança e do Adolescente, funcionam como uma instância estratégica do Sistema de Garantia de Direitos de Crianças e Adolescentes ${ }^{1}$. Com a função de proteção e garantia de direitos desse segmento populacional, os Conselhos se revestiram de um órgão de punição, e seus atores, os conselheiros tutelares, parecem muitas vezes reduzidos a essa perspectiva. A necessidade de conhecer melhor o que pensam, como constroem e realizam as suas funções de conselheiro, e o que identificam como impasses à sua prática se faz urgente, a fim de ultrapassar essa redução. E mais urgente, ainda, revela-se a necessidade de colocar lado a lado a análise dos sentidos de ser conselheiro tutelar mobilizando dois universos associados e carregados de expressões e sentidos do senso comum e mobilizadores de afetos: a violência contra crianças e adolescentes com deficiências. Com relação à violência contra crianças e adolescentes não são poucos os estudos ${ }^{2-7}$, cabendo então explorar esse universo especificando-o na direção dos agravos infringidos, e suas consequências no desenvolvimento e saúde, contra crianças e adolescentes com deficiências.

A violência contra crianças e adolescentes com deficiência se faz presente nas formas clássicas dos diversos tipos de abuso e nos processos de comunicação, organização familiar, institucional e comunitária ${ }^{5}$. A invisibilidade social deste grupo nos leva a supor da sua maior vulnerabilidade face às diversas práticas de violências praticadas. Dados oficiais ${ }^{8,9}$ apontam que crianças e adolescentes com deficiências (13,5\% do total das pessoas com deficiência no Brasil) estão mais propensos a terem seus direitos violados.

A violência se dá com maior intensidade pela existência de uma importante assimetria de poder entre vítima e agressor, e é agravada quando este grupo populacional tem alguma deficiên$\mathrm{cia}^{10-12}$. Entre outros fatores encontram-se aqueles associados a questões ambientais e estruturais, a carência de serviços educacionais, de saúde e de reabilitação adequados ${ }^{12-14}$.

Uma busca bibliográfica das produções científicas em saúde, através de um levantamento na biblioteca virtual em saúde Bireme apontou 99 referências através da palavra-chave "conselho tutelar”. Contudo, ao se utilizar a palavras-chave "conselheiro tutelar" para acessar os próprios conselheiros e sua prática como objeto de pesquisa, este número foi reduzido para dois. A primeira publicação no âmbito da psicologia bus- cou refletir sobre o papel do conselho tutelar na sociedade a partir de uma experiência de estágio curricular em Psicologia Jurídica nos cursos de graduação em Psicologia no Brasil ${ }^{15}$. Já a segunda publicação, também referida à psicologia, apresenta um relato de experiência de atendimento, em Plantão Psicológico, de uma criança vítima de abuso sexual intrafamiliar, encaminhada para uma Delegacia de Defesa da Mulher ${ }^{16}$. Contudo, ambas produções não comtemplam as especificidades da prática de Conselheiros Tutelares.

A fim de incrementar o conhecimento sobre as relações de vulnerabilidade a que estão expostas crianças e adolescentes com deficiências, a pesquisa "Crianças e Adolescentes com Deficiência em Situação de Violência: uma análise das notificações de maus-tratos", aprovada pelo CEP/ IFF, se organizou em duas vertentes metodológicas: a epidemiológica que foi centrada na análise dos fatores de vulnerabilidades identificados em 7319 das 9982 notificações registradas nos 08 Conselhos Tutelares da Região Metropolitana do Rio de Janeiro no ano de 2009; e a análise de narrativas produzidas em entrevistas com 14 conselheiros tutelares desses conselhos. Aos conselheiros foram atribuídos nomes fictícios, respeitados os princípios de autonomia, confidencialidade e voluntariedade na ética em pesquisa, com leitura e assinatura do TCLE.

O presente artigo focaliza os dados advindos da análise das narrativas dos conselheiros organizados em duas vertentes: 1) os sentidos do trabalho como conselheiro, englobando as perspectivas sobre a escolha dessa função, as relações com a sua formação e os enfrentamentos cotidianos; 2) os sentidos atribuídos pelos conselheiros à criança e aos adolescentes com deficiências submetidos às situações de violência.

\section{Abordagem Metodológica}

A abordagem metodológica centrou-se na análise narrativa dos sentidos da violência contra crianças e adolescentes com deficiências por meio da hermenêutica de profundidade de Thompson ${ }^{17}$. Esta escolha metodológica ocorreu em função da consideração de que as notificações de violências contra crianças e adolescentes com deficiência mobilizam no conselheiro tutelar referências ideológicas sobre poder e responsabilidade para garantir direitos, embutidas no exercício de sua função. Essas referências ideológicas e até existenciais referem dimensões de poder que constituem os sentidos produzidos pelos atores a partir 
da relação entre situação e contexto, e que podem ser exploradas por meio da hermenêutica de profundidade.

Para analisar o sentido dessas formas simbólicas produzidas em situação de entrevista, em uma dimensão micro analítica, lançamos mão da Análise Narrativa ${ }^{18-21}$, que examina a fala considerando a organização (sobretudo temporal) da experiência ${ }^{22}$, na qual se articula uma disjunção entre evento narrativo (no caso, a entrevista) e o evento narrado. Tal configuração favorece o exame do sentido das formas simbólicas da violência contra a criança e o adolescente, que se faz em reconhecimento da localização social e do contexto no qual as pessoas estão inseridas, que fornecem aos indivíduos diferentes graus de poder, isto é, da capacidade que cada pessoa tem de tomar decisões, conseguir seus objetivos e realizar seus interesses.

Foram realizadas entrevistas em 8 Conselhos selecionados pelo critério de representarem mais de 100.000 crianças e adolescentes. Em cada um dos 8 Conselhos buscou-se entrevistar dois conselheiros que tivessem conduzido casos relacionados às situações de violência contra crianças e adolescentes com deficiência e se recordassem dos casos tratados na sua gestão. Ao mesmo tempo, que os mesmos, durante a etapa de levantamento epidemiológico dos dados nos arquivos, travassem conversas informais que permitissem sua identificação por meio desses critérios. Em um dos Conselhos Tutelares só conseguimos que 1 conselheiro concordasse com a entrevista. Com isso totalizaram 15 entrevistas.

A entrevista narrativa, isto é, a entrevista que busca favorecer a emergência de narrativas na fala dos entrevistados ${ }^{19,23}$ e assim empoderá-los, teve como questão deflagradora variações da formulação me conte como escolheu ser conselheiro tutelar e como nessa história foi seu encontro com violências contra crianças e adolescentes com deficiências. Após essa questão colocada, solicitávamos que narrasse, caso não tivesse sido narrado antes, uma situação por ele atendida referida a esse segmento.

\section{Resultados}

As 15 entrevistas, após transcritas, lidas e analisadas, geraram o Quadro 1, construído com base na Hermenêutica de Profundidade de Thompson $^{17}$, adaptada ao nosso objeto de pesquisa:

No Quadro 1 ressaltamos que, na vertente da análise sócio-histórica, dentre as cinco possibilidades de análise (situações espaço-temporais, campos de interação, nível institucional, estrutura social e meios técnicos de transmissão),

Quadro 1. Perspectiva teórico-analítica das entrevistas

\begin{tabular}{|l|l|l|l|}
\hline Análise sócio-histórica & $\begin{array}{l}\text { Situações } \\
\text { espaço-temporais: } \\
\text { função do conselheiro } \\
\text { tutelar (compromissos, } \\
\text { papel social atribuído) }\end{array}$ & $\begin{array}{l}\text { Campos de interação: } \\
\text { escolhas pela função de } \\
\text { conselheiro, experiências } \\
\text { anteriores, trajetórias e } \\
\text { oportunidades }\end{array}$ & $\begin{array}{l}\text { Nível institucional: regras, } \\
\text { normas, acordos, recursos, } \\
\text { práticas e atitudes } \\
\text { disponíveis construídas } \\
\text { pelos conselheiros }\end{array}$ \\
\hline $\begin{array}{l}\text { Análise narrativa do } \\
\text { discurso: } \\
\text { pelementos - } \\
\text { personagens e eventos }\end{array}$ & $\begin{array}{l}\text { Personagens: } \\
\text { Estado } \\
\text { Familiares } \\
\text { Vizinhança } \\
\text { Abusadores } \\
\text { Criança e adolescente } \\
\text { com deficiências } \\
\text { Irmãos de crianças } \\
\text { e adolescentes com } \\
\text { deficiências }\end{array}$ & $\begin{array}{l}\text { Eventos/situações que levam } \\
\text { à violência: } \\
\text { Dificuldades de acesso } \\
\text { à saúde, lazer, educação, } \\
\text { moradia por falhas na } \\
\text { públicas } \\
\text { Vulnerabilidade pela situação } \\
\text { de pobreza e rede de apoio } \\
\text { Maus-tratos imputados por } \\
\text { familiares e estranhos }\end{array}$ & $\begin{array}{l}\text { Eventos } \\
\text { que contribuem para } \\
\text { o enfrentamento da } \\
\text { violência: } \\
\text { Empoderamento das } \\
\text { famílias } \\
\text { Identificação de parceiros } \\
\text { instionais }\end{array}$ \\
\hline $\begin{array}{l}\text { Interpretação / } \\
\text { reinterpretação: } \\
\text { síntese interpretativa }\end{array}$ & $\begin{array}{l}\text { 1) os sentidos do trabalho como conselheiro, englobando as perspectivas sobre } \\
\text { a escolha dessa atividade de trabalho, as relações com a sua formação e os } \\
\text { enfrentamentos cotidianos; } \\
\text { 2) os sentidos da criança e do adolescentes deficiente submetidas às situações de } \\
\text { violência. }\end{array}$ \\
\hline
\end{tabular}


optamos pelos três primeiros níveis de análise dada a adequação requerida pelo nosso objeto de pesquisa. Essa adequação fala da análise de narrativas de conselheiros tutelares destacando os sentidos de garantir direitos de um segmento particular de crianças e adolescentes, os que vivem com deficiências. E pela novidade e surpresa que a discussão apresentada pela pesquisa provocou nos conselheiros entrevistados, assim como pela relevância que apontaram como intrínseca a esse objeto, procuramos focalizar elementos de nível micro e meso, e menos aqueles relativos à estrutura social e meios de transmissão, de ordem macro.

Esclarecemos ainda que das cinco possibilidades para a análise formal ou discursiva apontadas pela Hermenêutica de Profundidade (semiótica, narrativa, argumentativa, sintática e discursiva) optamos pela análise narrativa de discurso, que nos conduziu a organizar os depoimentos de acordo com dois elementos: o dos personagens presentes na narrativa dos conselheiros e o dos eventos/situações, que, por sua vez, foram organizados a partir de duas ordens, as que levam à violência e as que podem enfrentá-la. Essa metodologia nos coloca diante de uma opção onde situação pessoal e contexto da estrutura social dialogam de forma a gerar uma síntese interpretativa na qual se destacam dois universos de sentidos: um relacionado à opção função de conselheiro e o aprendizado em comunidade de prática e o que isso gera, e outro referente aos processos de reconhecimento das situações de vulnerabilidade e riscos a sua integridade a que crianças e adolescentes com deficiências estão expostos e os sentidos desse reconhecimento ${ }^{24}$.

\section{Discussão}

\section{Os sentidos do trabalho como conselheiro: a escolha do oficio, $o$ aprendizado prático e os enfrentamentos cotidianos}

Nesse núcleo ganham destaque os sentidos de uma prática como conselheiro tutelar ligado a um reconhecimento atribuído por outros (conselheiros, amigos, familiares, comunidade) de que teriam competência para se tornar candidatos e exercerem o mandato nos conselhos tutelares. A conselheira 6, por exemplo, ao narrar sua decisão de se candidatar ao conselho, traz não apenas a voz do outro, mas também seu envolvimento religioso: eu tava sempre colocando essas questões ... mas eu acho que não vai dar ai eu vou me aborrecer eu vou querer trazer as crianças todas pra casa todas aquelas coisas aqueles quadros que a gente vivencia mesmo mas que já imagina que ia vivenciar ... e ai as pessoas falavam assim ah: mas você vai tirar de letra se você gosta você vai aprender você vai conseguir ... aí começaram a incentivar e aí [...] foi assim me coloquei em oração ... né e fui pedi pra que se fosse a vontade de Deus que essa vontade crescesse em mim né...

A grande maioria refere historias pessoais como donos de escolas, professores, gestores de abrigos para crianças e adolescentes, militantes da pastoral da criança e de combate a desnutrição materna e infantil. Também a conselheira 3 relata seu envolvimento com a Associação de Moradores e a Igreja Católica: ... eu comecei o trabalho assim com criança e adolescente na associação de moradores na época do projeto crescer ... né então assim fazia parte da associação ai tinha o leite que era distribuído pras crianças carentes e eu na época trabalhava na associação ... e na igreja católica ... com catequese pastoral da criança é mutirão de combate à desnutrição materna infantil então assim a minha história até chegar no conselho. Veio dessa militância né, do movimento social, do movimento popular.

A conjugação de um reconhecimento atribuído por outras pessoas com experiências como conselheiros tutelares, a uma perspectiva de competência a ser exercida em um mandato representativo, coletivo e ao qual precisa ser assumido de forma efetiva, leva a buscar a candidatura. Esse processo conduz a um aprendizado de mediação de conflitos para garantia de direitos em um lócus de comunidade de prática ${ }^{24,25}$ : aqui em [nome do municipio] você tem jogo de cintura, você vai a uma você vai a outro, você usa o seu conhecimento, você usa da sua atribuição e aí você consegue. Pelo menos eu consigo, você fica ali até conseguir, até aquilo acontece (Conselheira Tutelar 2). O essencial desse conceito relido à luz dos dados gerados pela pesquisa nos faz resgatar o sentido antropológico do conhecimento produzido em um ambiente coletivo, fruto de relações de alteridade, reconhecimento e apropriação sob a ótica dos seus praticantes. O essencial desse conceito na área de estudos sobre atuação de conselheiros tutelares na garantia dos direitos de crianças e adolescentes em geral, e em especifico do segmento que vive com deficiências, reside na possibilidade de suprir as falhas da estrutura social - como a invisibilidade imposta a esse segmento - e ao mesmo tempo não sucumbir (desistindo do mandato ou adoecendo). Isso porque é essencial refletir na potência dos arranjos e do 
trabalho em conjunto, que pode levar à associação entre diversos atores, criatividade e habilidade para resolver problemas advindos desse processo de aprendizado prático. Desta forma, é pertinente que as capacitações contemplem reflexões, práticas informais que contribuam para a aprendizagem cotidiana.

A dimensão do poder presente nesse lócus de formalidade e informalidade da aprendizagem de prática merece ser considerada, valendo ser ativada para aqueles que estão mais expostos e enfraquecidos pelo trabalho. Uma narrativa aponta como advém o enfrentamento das barreias cotidianas: só fazer encaminhamento não resolve. Eu vou a escola, me meto em todos os movimentos políticos [...] reuniões do Conselho da Pessoa com Deficiência, Conselho Municipal de Defesa da Criança e do Adolescente, audiências públicas (Conselheira Tutelar 1). A conjugação da participação em fóruns públicos, em espaços de proposição e de influência às tomadas de decisão, desvela os sentidos de uma militância que surge como traço comum à maioria dos conselheiros: Começou assim, eu com a minha cunhada tinha um grupo de ações de sociais, todo final de semana, ia para as comunidades... ai começou o interesse, né? Aî começa a ler o ECA, né? Começa a sentir cheia de poder. Mais também, né? O poderzinho vai caindo. Aí eu fiz a prova, inscrição, prova. Consegui passar, agora também tô fazendo faculdade serviço social para poder completar, né? Um lado puxa o outro. (Conselheira Tutelar 7).

Frente aos limites institucionais e dos recursos para o exercício da função de forma digna, os conselheiros reconhecem a possibilidade de gratificação por meio do encontro com a satisfação de poder resolver: Quando eu vou lá no COMPED e brigo e olha precisa de escola. Ai eles colocam, agora tem uma pessoa especial cuidando exatamente dessa área pra especiais da educação. Eu sei também que de ir lá e tanto encher o saco, que eu falei, ó, tem que prestar atenção, vamos lá, entendeu? Então eu acho que se a gente fazer um pouquinho cada um, cada um fazer um pouquinho, a gente muda, dá trabalho, mas muda e essa é minha maior satisfação, que a gente vê muito retorno, muito retorno (Conselheira Tutelar 1).

No extrato do discurso acima, assim como nas conversas informais com os atores durante a pesquisa, foi possível reconhecer a necessidade de influenciar atores situados em instâncias chave para fazer valer direitos de crianças e adolescentes. Essa capacidade de influenciar é cultivada e estimulada, e em nossa análise quando bem sucedida gera sentimentos de satisfação que com- pensam a precariedade da estrutura material de trabalho. É gerado um círculo virtuoso ${ }^{26}$ de reconhecimento e participação na relação com atores sociais chave, da comunidade ou das instituições jurídicas (juízes e promotores) que se revelam aliados em fazer valer os dispositivos legais e cobrar do Estado a criação e a implementação de Casas-Dia, Centros para Pessoas com Deficiência, Centros de Atenção Psicossocial para a Infância e Adolescência, dentre outros. A perspectiva de que a estrutura de uma rede articulada e efetiva para proteção e garantia de direitos se dá por meio de um movimento pró-ativo: Todo mundo fala, os conselhos tutelares precisam de estrutura técnica, eu acho que a gente precisa é de estruturar, estruturar, [...] a nova política da assistência social, ela já dá o suporte a essa técnica, a gente não tem que brigar, a gente tem que trabalhar em conjunto, entendeu? Pra trabalhar em conjunto você tem que levantar e sair lá, conversar, olha, o que ta acontecendo, o que você pode me ajudar, o que eu posso te ajudar? Tem que existir essa fala, a gente tem que levantar da cadeira e começar a falar cara a cara (Conselheira Tutelar 1).

Outro aspecto digno de nota diz respeito à capacidade de refletir sobre a própria prática. Identificam que muitas vezes existe uma sobrecarga de trabalho associada à precariedade das condições materiais para trabalhar (ausência de transporte próprio do conselho tutelar para realizar visitas domiciliares e visitas às instituições; sedes com estrutura predial inadequadas, com espaços impróprios para as atividades do conselho, como ausência ou salas inadequadas para atender os denunciantes (público atendido), sala de acolhida para as crianças e adolescentes a serem encaminhados ou para abrigos ou para a família, banheiros precários tanto para os trabalhadores dos conselhos quanto para o público atendido; precariedade no registro eletrônico das informações e locais inadequados para guarda em segurança dos documentos, resguardando-os inclusive das enchentes e poeira). Essas condições geram limites de atuação do conselheiro, que acaba sendo visto como um inimigo ou ameaçador ao poder da família, e não como um potente ator na construção de alicerces para criação e fortalecimento de redes de apoio.

E dentre essas famílias situamos aquelas cujos filhos são crianças e adolescentes que vivem com deficiências, e que pela situação de pobreza e de violação de direitos básicos pelo Estado acabam sucumbindo a situações em que seus filhos ficam sob a guarda de irmãos sem deficiência, que ficam eles mesmos sujeitos à negligência. Dos ca- 
sos citados pelos conselheiros, não era incomum identificar crianças e adolescentes saudáveis sofrendo em função da deficiência de seus irmãos e da carência de condições adequadas de vida.

Por fim, ganha destaque na quase totalidade das narrativas dos conselheiros, diversos elementos ligados ao adoecimento pelo trabalho. $\mathrm{O}$ conselheiro tutelar 4 entende que: Sofro bastante porque a gente é, eu costumo dizer que aqui você fica tentando é: descobrir o limite do ser humano e isso faz muito mal, eu nesses últimos três anos, eu envelheci eu adoeci por conviver com isso e tentar ter alguém pra conversar e não ... as pessoas [...] ai fui buscar tratamento mental psíquico terapia: uns falam terapia eu fui direto se eu mando todo mundo pro (IPUB) é melhor ir lá vê qual é... Tomo meus medicamentos faço a minha terapia porque assim fiquei doente.

$\mathrm{O}$ adoecimento pelo trabalho vem por vezes ligado também ao fato de que a função de conselheiro exige respostas efetivas, que caso não sejam dadas podem desencadear um processo de exposição pública e de perda de mandato. Essa perda de mandato, atribuída por meio de uma votação da comunidade a que pertence o conselheiro, acaba por funcionar como mais um elemento de pressão, no sentido de conservar uma imagem de poder e resolutividade: é muito difícil porque assim o conselheiro em si ele não tem, é muita tensão o tempo todo, é muita cobrança em cima dele e a gente tem que atender mesmo se não é processo. Vai ter que responder. Você fica com medo de ser envergonhado perante a sua comunidade porque vocêser afastado, você perder o mandado é uma coisa que você fica sempre com aquela pressão. Você percebe, a responsabilidade é toda nossa (Conselheira Tutelar 8).

Nesse aspecto cabe uma análise sobre as formas de lidar com a sensibilidade que se exacerba no contato com as denuncias em geral, mais especificamente aquelas referidas às crianças e adolescentes com deficiências. Ou seja, o exercício de garantir os direitos de crianças e adolescentes desvela expressões de indignação, horror, impotência que se reúnem às precariedades das condições materiais e de articulação efetiva no sistema de garantia de direitos para exercer dignamente seu trabalho.

\section{Os sentidos da criança e do adolescente deficiente submetidas às situações de violência}

Nas narrativas estudadas, determinadas leituras sobre a violência dirigida contra crianças e adolescentes com deficiência e sua possível notificação comparecem relacionadas às expressões omissão, família guardar para si, tristeza, gravidade. Essas categorias êmicas utilizadas pelos atores, levam a situar essas crianças na interface entre as instituições de saúde (hospitais, ambulatórios) e de segurança (delegacias, disque-denúncia) e o papel das famílias que muitas vezes por falta de recursos, redes de conhecimento e apoio, suportes terapêuticos e institucionais, mantém seus filhos em condições sub-humanas: ... ele ficava amarrado. Comia na mesma vasilha: era ele, o cachorro e a menina [irmã de 5 anos] (Conselheiro Tutelar 12).

A relação de vulnerabilidade e desamparo a que estão expostas as crianças e adolescentes com deficiência, revela-se violenta não somente para eles, mas muitas vezes para os irmãos "saudáveis", que em função da presença da criança e do adolescente com deficiências, precisam funcionar apoiando, cuidando e, por isso mesmo, se vêem submetidos eles próprios a uma posição na qual predomina a impossibilidade de serem cuidados, estudarem, e de serem crianças. Essa análise encontra eco na discussão de Goldson ${ }^{12}$ e Gonzalvo ${ }^{11}$, que assinalam em pesquisas diferentes que a presença de um familiar com deficiência pode funcionar como um fator de vulnerabilidade social.

Cabe ressaltar ainda, que as denúncias de violências contra crianças e adolescentes com deficiências, são feitas na sua maioria por vizinhos, que parecem, segundo os conselheiros, terem dúvidas em fazê-las, tendo como argumentos o fato de: 1) essas crianças e adolescentes demandarem muitos esforços e "sacrifícios" dos pais aos olhos do senso comum, e por isso mesmo tudo que é feito parece ser o máximo possível para manter sob controle e suprir falhas de um sistema de reabilitação e suporte escolar, pelo universo familiar; 2) esse esforço acaba por ser explicado, pelos vizinhos, segundo os conselheiros, como um assunto da intimidade daquela família, resguardado pelo segredo. O que faz esse segredo ser rompido é muitas vezes um conflito e/ou discordância entre os vizinhos e a família da criança ou adolescente vitima de violências. Ou seja, é um problema tornado público no âmbito da convivência externa ao mundo da casa, que alcança a rua. Dessa forma, a denuncia ao Conselho Tutelar parece reforçar a imagem punitiva, de "retirada do direito de ser pai e mãe", e não um registro que se respalda no reconhecimento do direito de crianças e adolescentes, e na possibilidade do Conselho comparecer como um ponto de rede de apoio para a família alvo do registro. 
Com relação às possíveis capacidades de definir e identificar crianças e adolescentes com deficiência, cujas demandas chegam aos Conselhos Tutelares, é comum utilizar as locuções "especial” ou "portador de necessidades especiais", indiscriminadamente, para referir àquelas crianças e adolescentes que possuem prejuízos em funções motoras, de linguagem, pensamento, controle de emoções.

Dessa forma, surge uma categoria geral e inespecífica, cujo registro na ficha de notificação acaba por não ganhar destaque, segundo alguns conselheiros por uma questão cultural. Surge um sentido relacionado ao anterior no que diz respeito ao que denominam questão cultural: a ausência de preocupação da população comum em associar possíveis alterações de funções vitais e de interação social como sinais de problemas dignos de atenção, assim como são as doenças físicas. É como se houvesse o predomínio de um olhar fisiopatológico nas avaliações sobre a saúde de crianças e adolescentes, que pode fazer passar despercebida a importância de garantir o desenvolvimento pleno e saudável, em suas diversas facetas, e que não corresponde a somente garantir a dimensão da saúde física.

Outra questão também encontrada, a partir do contato não só com os conselheiros tutelares, mas também com alguns integrantes das equipes técnicas dos conselhos, é a não diferenciação entre criança e adolescentes ditos normais e aquelas com deficiência, como a afirmação de uma técnica de que na sua prática não estabelecia diferença, pois para ela todas são crianças. Ou seja, não há uma percepção da possibilidade de vulnerabilidade das crianças e adolescentes em função de suas condições de pessoas com deficiência, e, por conseguinte, das suas limitações de reação e enfrentamento face às situações de violência sofridas.

No momento de interpretar os significados da violência e de seu trabalho com as notificações relacionadas às crianças e adolescentes com deficiência, os conselheiros evocam um repertório de experiências pessoais, que classificam todas sem distinção como "especiais, excepcionais, deficientes ou doentes mentais”. Essa indiferenciação entre deficiência e doença mental prejudica ações de saúde e educação adequadas e diferenciadas para cada grupo dessas crianças e adolescentes. $\mathrm{O}$ conselheiro 4 aponta: agora quanto à deficiência todos nós somos deficientes, deficientes em atender deficientes em informações nós não sabemos nem a forma correta de você se dirigir a alguém com deficiência eu não sei se ... por exemplo uma pessoa com comprometimento mental eu não sei se chamo de doido de maluco você fica assim com medo de não tá sendo politicamente correto.

As solicitações para avaliações de fonoaudiologia e neurologia são citadas como podendo ocorrer caso a criança apresente alterações significativas de linguagem e comportamento, e isso venha acompanhado de solicitações da família e da escola. Mas, a informação na ficha de notificação só ganha o registro de alguma deficiência relacionada à criança ou ao adolescente caso a família possua o registro do Código Internacional de Doenças (CID). Com relação ainda ao tema do diagnóstico ou de tudo que cerca a capacidade de reconhecer as deficiências com vistas a gerar um registro, um aspecto que comparece ligado à resistência dos médicos em fornecer um laudo para acesso ao Beneficio de Prestação Continuada (BPC). Essa observação surgida em tom de crítica é interpretada como um medo de assumir ou falta de conhecimento.

A interpretação que liga viver com uma deficiência a um fator de vulnerabilidade esteve presente na fala de um conselheiro, que também identifica as relações entre o não reconhecimento social e setores marginais da sociedade: A gente vê que os problemas neurológicos na infância, depois eles acabam sendo braços do tráfico, porque não são tratados. Mas quem disse que a gente consegue neurologistas para todas as crianças, exames, remédios? (Conselheira Tutelar 1 ). Outro aspecto referido como um índice de algo não está bem com a criança ou o adolescente diz respeito ao universo relacional e à prática de bulliyng pelos colegas, que acaba chegando ao conselho tutelar como um pedido de ajuda encaminhado em função das reações da criança ou do adolescente vítima dessa prática.

\section{Conclusão}

As situações de sofrimento, dada à carga de gravidade das questões que chegam aos conselhos tutelares, no sentido de violações estruturais de direitos (moradia, educação, saúde, lazer, convivência familiar e comunitária) e de todas as manifestações da violência interpessoal, são citadas como fatores de sofrimento, e, em seu extremo, de adoecimento pelos conselheiros. Essa carga de trabalho e suas interfaces emocionais podem gerar duas respostas: a) aquela que busca tecer redes por meio de conhecimentos informais e aprendizados no cotidiano, que geram repertório relacional e de conhecimento, ambiente de comunidade de prática, e que assim contribuem para 
o trabalho de garantia de direitos; b) outra que pode reforçar, pela dificuldade de gerar interfaces relacionais, de acionar o sistema de garantia de direitos e de fazê-lo operar, o papel da representação dos conselheiros como agentes repressores e a quem se deveria temer, por "retirar crianças e adolescentes de suas famílias". Acreditamos que o investimento no capital simbólico e humano das trocas, da aprendizagem baseada nos problemas da atuação como conselheiro, pode contribuir para superar reducionismos na imagem pública e na autoimagem que os próprios conselheiros constroem do seu trabalho.

Com relação ao segmento de crianças e adolescentes com deficiência, identificamos sentidos que o tratando de forma indiferenciada como especial, acaba por reforçar sua invisibilidade, inespecificando estatísticas e dados que poderiam gerar políticas e campanhas sintonizadas com o enfrentamento das violências contra esse público. Outra questão diz respeito ao fato de que saber as diferenças entre pessoas com deficiências intelec- tuais e doentes mentais, por exemplo, tem consequências em encaminhamentos e articulação de redes para diagnóstico, tratamento e reabilitação. Consideramos que essa inespecificidade faz parte de um acúmulo de carências, inclusive no repertório técnico dos profissionais da área de saúde e educação, que por motivos diversos, desde sobrecarga de trabalho, falhas na formação, ausência de instrumentos adequados de registro, não conseguem esclarecer as necessidades diferenciadas que cada segmento de crianças e adolescentes com deficiências, doenças mentais, doenças crônicas, podem gerar.

Nessa direção, assinalamos como desejável a ampliação de estudos que façam interface entre saúde da criança e do adolescente e os direitos de crianças e adolescentes com deficiências e doenças crônicas, com o enfrentamento da violência e o suporte à informação qualificada que subsidie a prática dos atores envolvidos com seus direitos, com destaque para os conselheiros tutelares.

\section{Colaboradores}

MCN Moreira, OM Bastos, LC Bastos foram responsáveis pela orientação teórica e metodológica do artigo, redação e revisão final. AHR Soares, WS Souza e RN Sanchez foram responsáveis pela revisão de literatura, redação e revisão final. 


\section{Referências}

1. Brasil. Lei 8.069, de 13 de julho de 1990. Dispõe sobre o Estatuto da Criança e do Adolescente e dá outras providências. Diário Oficial da União 1990; 16 jul.

2. Rocha PCX, Moraes CL. Violência familiar contra a criança e perspectivas de intervenção do Programa Saúde da Família: a experiência do PMF/Niterói (RJ, Brasil). Cien Saude Colet 2011; 16(7):3285-3296.

3. Assis SG. Aspectos conceituais da violência na infância e adolescência. In: Lima CA, coordenadora. Violência faz mal à saúde. Brasília: Ministério da Saúde (MS); 2006. (Séries B - Textos Básicos de Saúde).

4. Reichenheim ME, Hasselmann MH, Moraes CL. Conseqüências da violência familiar na saúde da criança e do adolescente: contribuições para a elaboração de propostas de ação. Cien Saude Colet 1999; 4(1):109121.

5. Deslandes SF. Atenção a crianças e adolescentes vítimas de violência doméstica: análise de um serviço. Cad Saude Publica 1994; 10(Supl. 1):S177-S187.

6. Reed E, Silverman JG, Raj A, Decker MR, Miller E. Male perpetration of teen dating violence: associations with neighborhood violence involvement, gender attitudes, and perceived peer and neighborhood norms. J Urban Health 2011; 88(2):226-239.

7. Cavalcante FG, Goldson E. Situational analysis of poverty and violence among children and youth with disabilities in the Americas - an agenda proposal. Cien Saude Colet 2009; 14(1):7-20.

8. Neri M, Pinto A, Soares W, Costilla H. Retratos da deficiência no Brasil (PPD). Rio de Janeiro: FGV, IBRE, CPS; 2003.

9. Fundo das Nações Unidas para a Infância (UNICEF). Situação Mundial da Infância 2011. [acessado 2011 jun 27]. Disponível em: http://www.unicef.pt/18/Relatorio_SOWC_2011.pdf

10. Tharinger D, Horton CB, Millea S. Sexual abuse and exploitation of children and adults with mental retardation and other handicaps. Child Abuse Neglect 1990; 14(3):301-301.

11. Williams LCA. Sobre deficiência e violência: reflexões para uma análise de revisão de área. Rev. Brasileira de Educação Especial 2003; 9(2):141-154.

12. Gonzalvo O. Maltrato en niños con discapacidades y factores de riesgo. Anales Españoles de Pediatría 2002; 56(3):219-223.

13. Goldson E. Maltreatment among children and adolescent with disabilities. Infants and Young Children 2001; 13(4):44-54.
14. Blum RWM. El adolescente com afecciones crónicas o discapacitantes. In: Maddaleno M, Bruner J, editors. Acts of meaning. Cambridge: Harvard University Press; 1990. p. 203-209.

15. Sequeira VC, Monti M, Braconnot FMO. Conselhos tutelares e psicologia: políticas públicas e promoção de saúde. Psicol. estud 2010; 15(4):861-866.

16. Ribeiro PW, Sequeira VC. O abuso sexual e a criança: o caso João e Maria. Bol iniciaç cient psicol 2005; 6(1):1932.

17. Thompson JB. Ideologia e cultura moderna. Rio de Janeiro: Vozes; 1995.

18. Riessman CK. Narrative Analysis. Newbury Park: SAGE; 1993.

19. Mishler E. Research interviewing. Context and narrative. Cambridge: Harvard University Press; 1986.

20. Mishler E. Storylines. Craftartists' Narratives of Identity. Cambridge: Harvard Univerity Press; 1999.

21. Bastos LC. Contando estórias em contextos espontâneos e institucionais - uma introdução ao estudo da narrativa. Calidoscópio 2005; 3(2):74-87.

22. Bruner J. Acts of meaning. Cambridge: Havard University Press; 1990.

23. Jovchelovitch S, Bauer M. Entrevista Narrativa. In: Bauer ME, Gaskell G, organizadores. Pesquisa Qualitativa com texto, imagem e som. Um manual prático. Petrópolis: Vozes; 2000. p. 90-113.

24. Wenger EC, Snyder WM. Communities of Practice: The Organizational Frontier. Harvard Business Review 2000; Jan-Feb:139-145.

25. Terra JC. Comunidades de prática: conceitos, resultados e métodos de gestão. [acessado 2013 abr 14]. Disponível em: http://biblioteca.terraforum.com.br/BibliotecaArtigo/ libdoc00000098v002Comunidades\%20de\%20Praticaconceitos, $\% 20$ resultad.pdf

26. Tocqueville A. A democracia na América. 3a ed. Belo Horizonte: Itatiaia; 1987.

Artigo apresentado em 19/07/2013

Aprovado em 20/01/2014

Versão final apresentada em 23/01/2014 
